\title{
Two-photon absorption and stimulated emission in poly-crystalline Zinc Selenide with femtosecond laser excitation
}

\author{
Qianliang Li®${ }^{1}$, Walter Perrie ${ }^{*}$, Zhaoqing Li $^{2}$, Stuart P Edwardson ${ }^{1}$ and \\ Geoff Dearden ${ }^{1}$
}

\begin{abstract}
The optical nonlinearity in polycrystalline zinc selenide (ZnSe), excited with $775 \mathrm{~nm}, 1 \mathrm{kHz}$ femtosecond laser pulses was investigated via the nonlinear transmission with material thickness and the $Z$ scan technique. The measured two photon absorption coefficient $\beta$ was intensity dependent, inferring that reverse saturated absorption (RSA) is also relevant during high intensity excitation in ZnSe. At low peak intensity $I<5 \mathrm{GW} \mathrm{cm}^{-2}$, we find $\beta=3.5 \mathrm{~cm} \mathrm{GW}^{-1}$ at $775 \mathrm{~nm}$. The spectral properties of the broad blueish two-photon induced fluorescence $(460 \mathrm{~nm}-500 \mathrm{~nm}$ ) was studied, displaying self-absorption near the band edge while the upper state lifetime was measured to be $\tau_{\mathrm{e}} \sim 3.3 \mathrm{~ns}$. Stimulated emission was observed when pumping a $0.5 \mathrm{~mm}$ thick polycrystalline ZnSe sample within an optical cavity, confirmed by significant line narrowing from $\Delta \lambda=11 \mathrm{~nm}$ (cavity blocked) to $\Delta \lambda=2.8 \mathrm{~nm}$ at peak wavelength $\lambda_{\mathrm{p}}=475 \mathrm{~nm}$ while the upper state lifetime also decreased. These results suggest that with more optimum pumping conditions and crystal cooling, polycrystalline ZnSe might reach lasing threshold via two-photon pumping at $\lambda=775 \mathrm{~nm}$.
\end{abstract}

Keywords: ZnSe; femtosecond laser; nonlinear absorption; stimulated emission; fluorescence

Li QL, Perrie W, Li ZQ, Edwardson SP, Dearden G. Two-photon absorption and stimulated emission in poly-crystalline Zinc Selenide with femtosecond laser excitation. Opto-Electron Adv 5, 210036 (2022).

\section{Introduction}

In recent years, significant efforts have been devoted to the wide band gap materials for next-generation optoelectronic devices ${ }^{1}$. ZnSe, is a semiconductor which has a cubic structure and a large direct bandgap of $2.7 \mathrm{eV}$ (with cut-off wavelength $\lambda=460 \mathrm{~nm}$ ). It has a high refractive index (RI) $n \sim 2.5$ in the optical region with a remarkably wide transmission band, transparent from the visible region near $\lambda \sim 550 \mathrm{~nm}$ to the far infrared (FIR), $\lambda \sim 18 \mu \mathrm{m}$, hence a versatile optical material for FIR laser lenses and windows ${ }^{2}$. Also, it is intensively identified as a suitable material for blue-light-emitting diodes and lasers sources. Such sources can be applied in a broad range of applications, including compact displays, optical storage in high-density DVDs and biomedical diagnostics $^{3,4}$. It is therefore interesting to study its properties such as absorption coefficient, nonlinear (NL) response and refractive index since $\mathrm{ZnSe}$ is promising for future applications in blue-violet electroluminescent devices.

The electronic energy-band structure of ZnSe was reproduced in ref. ${ }^{5}$ while the RI real and imaginary part

${ }^{1}$ Laser Engineering Group, School of Engineering, University of Liverpool, Liverpool, L69 3GQ, United Kingdom; 2 Laser Processing Research Centre, School of Mechanical, Aerospace and Civil Engineering, University of Manchester, Manchester M13 9PL, United Kingdom.

*Correspondence: W Perrie, E-mail: wpfemto1@liverpool.ac.uk

Received: 15 March 2021; Accepted: 10 June 2021; Published online: 25 January 2022

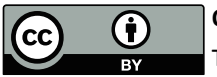

Open Access This article is licensed under a Creative Commons Attribution 4.0 International License.

To view a copy of this license, visit http://creativecommons.org/licenses/by/4.0/.

C The Author(s) 2022. Published by Institute of Optics and Electronics, Chinese Academy of Sciences. 
and the absorption coefficient were published in ref. ${ }^{6}$. The investigation of the nonlinear optical properties of ZnSe is crucial since two-photon absorption imposes a fundamental limitation on the performance of all optical switching devices ${ }^{1}$. The surface and bulk absorption characteristics of $\mathrm{ZnSe}$ was reported at wavelengths of $2-20 \mu \mathrm{m}$ and temperature $100-500 \mathrm{~K}^{7}$. The edge of transparency of polycrystalline $\mathrm{ZnSe}$ is $550 \mathrm{~nm}$, and the melting temperature is $1790 \mathrm{~K}^{8}$. Table 1 summarises laser based measurements of NL properties of single crystal (SC) and polycrystalline (PC) ZnSe. Most efforts have understandably been on single crystal material with fewer defects. The changes of reflectivity, absorption coefficient, optical and dielectric constants with the photon energy $(2-26 \mathrm{eV})$ for single crystal $\mathrm{ZnSe}$ were published in ref. ${ }^{9}$. The linear absorption coefficient of single crystal ZnSe at wavelength $\lambda=448 \mathrm{~nm}$ and $2 \mathrm{~K}$ was reported to be $4 \mathrm{~cm}^{-1}{ }^{10}$. Some electrical and optical properties of single crystal ZnSe was reported in ref. ${ }^{5,6,11,112}$.

Lasing in SC ZnSe has been observed using electron beam ${ }^{25,26}$ and optical pumping ${ }^{27,28}$. In the former, a high density of electron-hole pairs can be easily excited deep into the $\mathrm{ZnSe}$ of the order of several micrometers with the injected electron beam ${ }^{4}$. However, the incident energetic electron beam can rapidly degrade the crystal and will not be considered further here. On the other hand, in the latter method, the penetration depth is reduced so that the energy is located near the surface of the $\mathrm{ZnSe}^{29}$. Luminescence from single crystal $\mathrm{ZnSe}$ excited by picosecond (5 ps) mid-infrared free-electron laser pulses $(9.5-11.0 \mu \mathrm{m})$ was reported ${ }^{30}$ and stimulated emission from single crystal ZnSe below $200 \mathrm{~K}$, induced by either one-photon or two-photon excitation has been observed $^{31}$. The lasing mechanism includes an electronhole plasma modified by self-absorption ${ }^{32,33}$, longitudinal-optical-phonons assisting the free exciton annihilation $^{31}$, an inelastic exciton-exciton scattering process ${ }^{31,34}$, a combination of exciton-exciton and exciton-photon processes $^{35}$ or many particles interactions ${ }^{36}$.

The research to date in the literature has concentrated on the linear and NL optical properties of single crystal ZnSe which is an expensive substrate and needs to be grown to specification. On the other hand, polycrystalline ZnSe substrates of required thickness and sizes are relatively easy to obtain commercially - and such material is still very pure. The availability of optically polished, polycrystalline substrates has driven the current interest in NL studies and the observation of stimulated emission in polycrystalline material reported here infers pure material with low defect density.

\section{Experimental setup}

As shown in Fig. 1, the pump source is a Clark-MXR femtosecond laser system operating at $775 \mathrm{~nm}$ with 200 fs pulse length, with an average power of $1 \mathrm{~W}$ at $1 \mathrm{kHz}$ repetition rate. The laser beam is attenuated, de-magnified $(\times 1 / 2)$ by a telescope and collimated transmitted pulse energy measured by a pyroelectric detector (Molectron 3Sigma J5-09). A quarter-wave plate allowed variation of the incident laser polarisation. The undoped polycrystalline ZnSe was supplied by Crystran Ltd. All experiments were carried out at room temperature (18 ${ }^{\circ} \mathrm{C}$ ), and the samples were cleaned and wiped with methanol prior to laser exposure. The pristine surface roughness was measured to be $R a=9.6 \pm 1.2 \mathrm{~nm}$, checked using a white light interferometer (WYKO NT1100).

Table 1 | Selection of literature to date on optical properties of ZnSe with laser excitation from fs to ps temporal pulse lengths.

\begin{tabular}{|c|c|c|c|c|c|c|}
\hline Form & Thickness (mm) & $\lambda(\mathrm{nm})$ & $\tau$ & $\beta(\mathrm{cm} / \mathrm{GW})$ & $n_{2}$ & Ref \\
\hline SC & 0.73 & 532 & $30 \mathrm{ps}$ & $12.3 \sim 14.9$ & - & ref. $^{1}$ \\
\hline PC & - & 532 & ps & 5.5 & - & ref. $^{13,14}$ \\
\hline PC & 2.7 & 532 & $27 \mathrm{ps}$ & 5.8 & $4.4 \times 10^{-11}$ esu & ref. ${ }^{15,16}$ \\
\hline PC & - & 532 & - & 5 & - & ref. ${ }^{17}$ \\
\hline \multirow{3}{*}{$\mathrm{PC}$} & \multirow{3}{*}{$1.5 \sim 3$} & 610 & $125 \mathrm{fs}$ & 2.4 & $<2.2 \times 10^{-12} \mathrm{esu}$ & \multirow{3}{*}{ ref. ${ }^{18}$} \\
\hline & & 780 & $75 \mathrm{fs}$ & 3.5 & $10 \times 10^{-12}$ esu & \\
\hline & & 1270 & $80 \mathrm{fs}$ & $<0.005$ & $3.5 \times 10^{-12} \mathrm{esu}$ & \\
\hline SC & 2 & $500 \sim 710$ & $165 \mathrm{fs}$ & $6.5 \sim 7.2$ & $(-3.5 \sim 1.5) \times 10^{-14} \mathrm{~cm}^{2} / \mathrm{W}$ & ref. ${ }^{19}$ \\
\hline SC & 2.5 & $700 \sim 980$ & $150 \sim 200$ fs & $0.1 \sim 7$ & $3 \times 10^{-14} \mathrm{~cm}^{2} / \mathrm{W}$ & ref. 20 \\
\hline PC & 1 & 790 & $200 \mathrm{fs}$ & $2.7 \pm 0.3$ & $(2.3 \pm 0.8) \times 10^{-11} \mathrm{esu}$ & ref. $^{21}$ \\
\hline SC & - & 1060 & $30 \sim 200$ ps & - & - & ref. ${ }^{22}$ \\
\hline SC & 1 & $1200 \sim 1950$ & $1 \mathrm{ps}$ & - & $(9.3 \sim 15.8) \times 10^{-6} \mathrm{~cm}^{2} / \mathrm{W}$ & ref. $^{23}$ \\
\hline PC & 2 & 3900 & - & - & $(1.2 \pm 0.3) \times 10^{-14} \mathrm{~cm}^{2} / \mathrm{W}$ & ref. ${ }^{24}$ \\
\hline
\end{tabular}




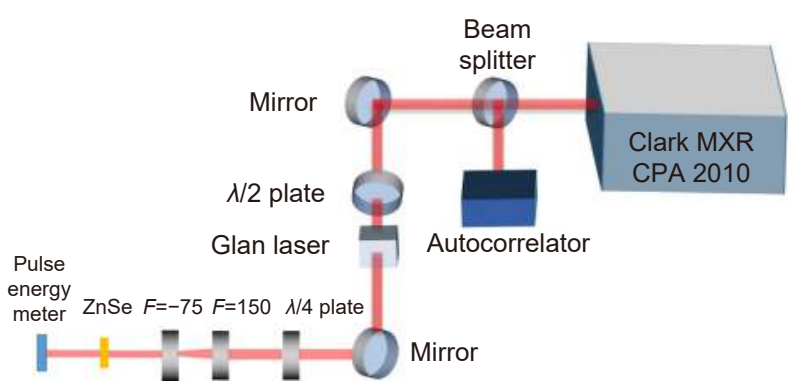

Fig. 1 | Schematic diagram of experimental set up for NL transmission measurements. An attenuated and de-magnified beam is directed to the ZnSe substrate where the external transmission can be measured. A $1 / 4$ plate allows incident polarisation to be altered from linear to circular.

\section{Results and discussion}

\section{Material analysis}

Polycrystalline Zinc Selenide supplied by Crystran Ltd is fabricated by the conventional chemical vapor deposition (CVD). It is synthesised from Zinc vapour and $\mathrm{H}_{2} \mathrm{Se}$ gas, forming as sheets on Graphite susceptors. The resultant material is ultrapure with grain size of $\mathrm{ZnSe}$ controlled to obtain maximum strength and stated to be $<100 \mu \mathrm{m}$. The crystals have the zinc blende structure or face centred cubic (FCC).

Polycrystalline ZnSe should have a very low Oxygen content due to processing route. The elemental composition of the ZnSe sample was determined with Energy Dispersive X-ray (EDX) analysis using scanning electron microscope (ZEISS Sigma). The zinc and selenide contents are $62.9 \%$ and $37.1 \%$ respectively and no trace of element $\mathrm{O}$ could be found Fig. 2. This is consistent with the high purity, quoted as $99.999 \%$.

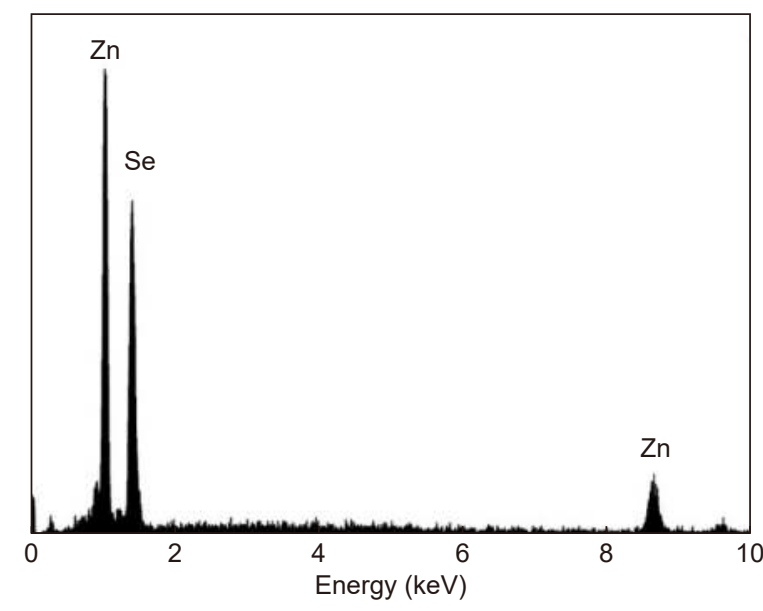

Fig. 2 | EDX image of $0.5 \mathrm{~mm}$ thick polycrystalline ZnSe.

\section{Optical properties}

The external optical transmission characteristics of 0.5 $\mathrm{mm}$ thick polycrystalline $\mathrm{ZnSe}$ was recorded using a spectrophotometer (SPECORD 250) in the wavelength range of 200 to $1100 \mathrm{~nm}$ in air at normal incidence. The variation of transmission with wavelength is shown in Fig. 3. The strong absorption around the cut off $\lambda=460$ $\mathrm{nm}$ indicates the bandgap $E_{\mathrm{b}} \sim 2.7 \mathrm{eV}$. The general appearance of this spectrum corresponds to the yellow colour of the sample observed under white light ${ }^{23}$. Between 470 and $530 \mathrm{~nm}$, the transmission increases rapidly while above $700 \mathrm{~nm}$, where dispersion is almost negligible, the external transmission approaches $T \sim 70 \%$ at $1100 \mathrm{~nm}$, limited only by the reflection losses due to the high refractive index. Linear absorption in the NIR is therefore very low indeed.

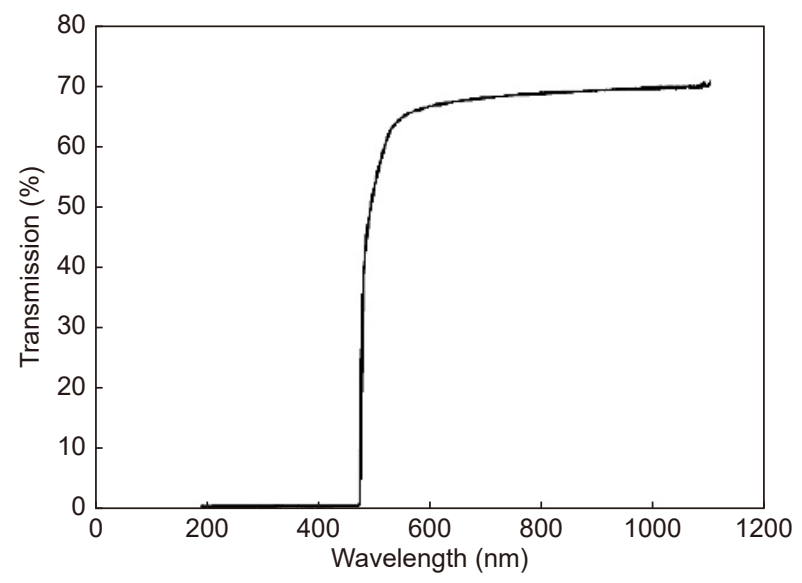

Fig. 3 The external transmission of ZnSe measured with a spectrophotometer, showing that the cut-off $\lambda \sim 460 \mathrm{~nm}, E_{\mathrm{b}}=2.7$ eV and high transparency in the NIR.

\section{Linear absorption under low intensity laser exposure}

Figure 4(a) shows the transmission curves with thickness and intensity under nanosecond laser exposure $(\lambda=$ $775 \mathrm{~nm}, \tau_{\mathrm{p}}=150 \mathrm{~ns}$ ) when the Regenerative amplifier was unseeded. The results infer a very low linear absorption coefficient $\alpha_{0}$. The external transmission is given by the Beer-lambert law ${ }^{37}$,

$$
T=(1-R)^{2} \mathrm{e}^{-\alpha_{0} z},
$$

where $\alpha_{0}$ is the linear absorption coefficient $\left(\mathrm{cm}^{-1}\right), z$ is the material thickness $(\mathrm{cm})$, and $R$ is the surface reflectivity of ZnSe in air. As refractive index $n=2.53$ at $780 \mathrm{~nm}, R=(n-1)^{2} /(n+1)^{2}=0.19$, hence, the loss by reflection is taken into account by the fraction $(1-R)^{2}=$ 0.66 . The observed transmission in Fig. 4(a) with varying thickness is consistent with an extremely weak linear absorption coefficient $\alpha_{0} \ll 0.1 \mathrm{~cm}^{-1}$.

The transmitted intensity changes as a function of the 
sample thickness with incident intensity $I_{0}=0.02 \mathrm{GW}$ $\mathrm{cm}^{-2}$ at $200 \mathrm{fs}$, as is shown in Fig. 4(b). No change in external transmission with sample thickness can be detected within experimental error.
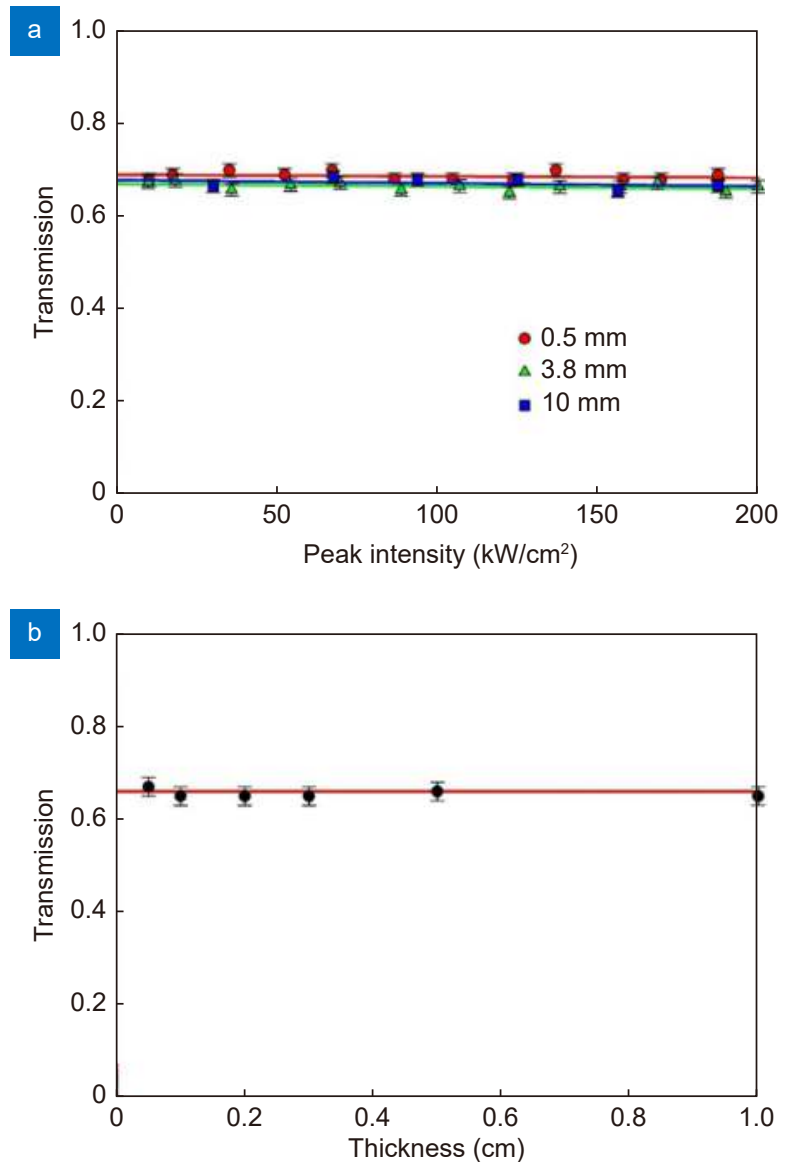

Fig. 4 | (a) Transmission curves with thickness of ZnSe and intensity with nanosecond exposure. (b) Transmission with sample thickness at intensity of $0.02 \mathrm{GW} \mathrm{cm}^{-2}$ with $200 \mathrm{fs}$ exposure at $775 \mathrm{~nm}$.

\section{Nonlinear absorption}

Open aperture $\mathrm{Z}$ scan $^{15}$ was performed to investigate the two-photon absorption coefficient of polycrystalline $\mathrm{ZnSe}$. Prior to the $\mathrm{Z}$ scan process, the optical alignment was carefully adjusted to ensure that the beam propagated horizontally along the desired optic axis at a fixed height. The pulse width $\tau=200$ fs (FWHM) was determined via the autocorrelator assuming a sech ${ }^{2}$ response. The Rayleigh range was determined by measuring the variation of beam spot size at different positions along the optic axis. The pulse width and energy were monitored during the scanning process. The incident pulse energy and transmitted pulse energy were measured using a calibrated pyroelectric detector (Molectron J5-09), which is able to measure every pulse at $1 \mathrm{kHz}$, producing the average energy and standard deviation. Peak intensities were then calculated from beam profiles and temporal pulse length. The sample was translated through the focal plane of a lens with focal length $f=250 \mathrm{~mm}$ while measuring transmitted pulse energy with the pyro-electric detector. Figure 5(a) shows the typical scans observed with peak incident intensities $I=24 \mathrm{GW} \mathrm{cm}^{-2}$ and $490 \mathrm{GW} \mathrm{cm}^{-2}$ respectively. The solid lines represent the best fit to Eq. (2) ${ }^{15}$,

$$
\Delta T(z) \approx \frac{q_{0}}{2 \sqrt{2}} \frac{1}{\left[1+Z^{2} / Z_{0}^{2}\right]},
$$

where the free factor $q_{0}=\beta I_{0} L_{\text {eff }}, \beta\left(\mathrm{cm} \mathrm{GW}^{-1}\right)$ is the twophoton absorption coefficient, $\left.I_{0}(\mathrm{GW} \mathrm{cm})^{-2}\right)$ is the peak intensity at the beam focus $(Z=0)$, the effective optical thickness $L_{\mathrm{eff}}=\left(1-\mathrm{e}^{-\alpha L}\right) / \alpha, L=5 \times 10^{-2} \mathrm{~cm}$ is the sample thickness, $\alpha\left(\mathrm{cm}^{-1}\right)$ is the linear absorption coefficient, and $\mathrm{Z}_{0}$ is the Rayleigh range of the beam. A series expansion of $L_{\mathrm{eff}} \sim L-\left(\alpha L^{2}\right) / 2=4.8 \times 10^{-2} \mathrm{~cm}$ (assuming
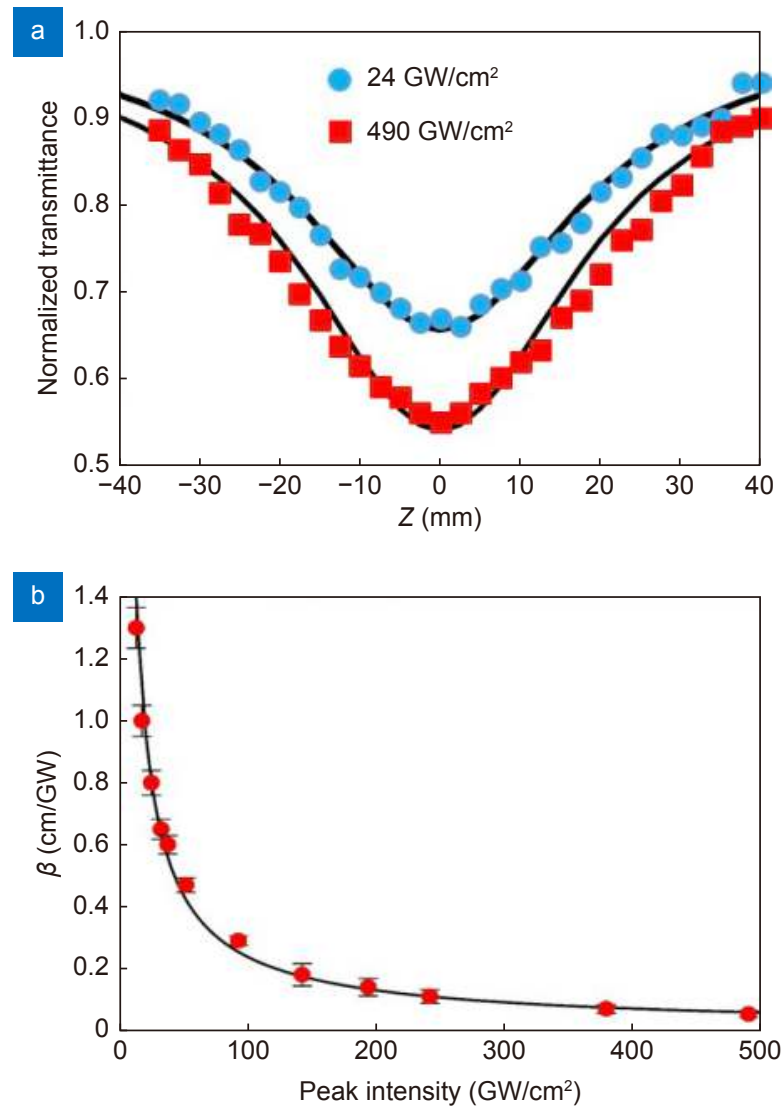

Fig. 5 | (a) Open aperture Z scan data of polycrystalline ZnSe at $I_{0}=$ $24 \mathrm{GW} \mathrm{cm}^{-2}$ and $490 \mathrm{GW} \mathrm{cm}^{-2}$ with best fits to $\beta=0.8 \mathrm{~cm} \mathrm{GW}^{-1}$ and $\beta=0.05 \mathrm{~cm} \mathrm{GW}^{-1}$ respectively. (b) Measured effective 2-photon absorption coefficient $\beta$ versus peak intensity of $0.05 \mathrm{~cm}$ polycrystalline ZnSe which reaches $\beta=1.3 \mathrm{~cm} \mathrm{GW}^{-1}$ at intensity $I_{0}=13 \mathrm{GW} \mathrm{cm}^{-2}$, decreasing to $\beta=0.05 \mathrm{~cm} \mathrm{GW}^{-1}$ at $490 \mathrm{GW} \mathrm{cm}^{-2}$. 
$\left.\alpha \sim 0.1 \mathrm{~cm}^{-1}\right)$, converging to $L$ as $\alpha \rightarrow 0$. With the $250 \mathrm{~mm}$ focal length lens, the beam Rayleigh length was measured to be $Z_{0}=10.5 \mathrm{~mm}$ so that $L_{\text {eff }} \ll Z_{0}$, required for this technique.

Figure 5(b) shows the measured two-photon absorption coefficient $\beta$ which is intensity dependent, which reaches $\beta=1.3 \mathrm{~cm} \mathrm{GW}^{-1}$ at intensity $I=13 \mathrm{GW} \mathrm{cm}^{-2}$, decreasing to $\beta \sim 0.05 \mathrm{~cm} \mathrm{GW}^{-1}$ at $490 \mathrm{GW} \mathrm{cm}^{-2}$. Since $\beta$ decreases with peak intensity, these results infer that reverse saturation absorption is also relevant during high intensity excitation ${ }^{38}$. The $\mathrm{Z}$ scan fits support NL twophoton absorption to the conduction band but there may be a contribution from higher order processes, e.g. threephoton absorption but more likely two-photon plus single photon excited state (free carrier) absorption $\left(\chi^{(3)}\right.$ : $\left.\chi^{(1)}\right)$. Hence, the absorption of a third (sequential) photon from $3.2 \mathrm{eV}$ to higher in the conduction band is relevant. The increase in $\beta$ below $I=24 \mathrm{GW} \mathrm{cm}{ }^{-2}$ is consistent with that measured by Tseng et $\mathrm{al}^{21}$ who found $\beta=2.7$ $\mathrm{cm} \mathrm{GW}^{-1}$ at intensity $I=0.95 \mathrm{GW} \mathrm{cm}^{-2}$ and $\lambda=790 \mathrm{~nm}$. However, extrapolation of our data to $I=0.95 \mathrm{GW} \mathrm{cm}^{-2}$ is likely unreliable and so requires data in this low intensity region, included below. The reflectivity and transmission are consistent with the values described in ref. ${ }^{39}$. The single pulse ablation threshold of SC ZnSe was reported to be $F_{\text {th }}=0.7 \mathrm{~J} \mathrm{~cm}^{-2}$ with $150 \mathrm{fs} / 800 \mathrm{~nm}^{40}$, and multi-pulse ablation threshold will be lower due to incubation. Our maximum fluence was estimated to be $F_{\max }=0.1 \mathrm{~J} \mathrm{~cm}^{-2}$ at $I=490 \mathrm{GW} \mathrm{cm}^{-2}$ to avoid ablation of $\mathrm{ZnSe}$ since Selenium is highly toxic.

The photon energy at $775 \mathrm{~nm}, h v=1.6 \mathrm{eV}$ is much lower than the direct band gap energy $E_{\mathrm{b}}=2.7 \mathrm{eV}$ while $2 h v>E_{\mathrm{b}}, 0.5 \mathrm{eV}$ above the two photon resonance of $\mathrm{ZnSe}^{21}$. It requires simultaneous absorption of two photons at $775 \mathrm{~nm}$ to reach the conduction band. Pure two-photon absorption is described by,

$$
\frac{\mathrm{d} I}{\mathrm{~d} z}=-\beta I(z)^{2},
$$

where $\beta$ is the two-photon absorption coefficient $(\mathrm{cm}$ $\mathrm{GW}^{-1}$ ). By integrating equation (3), the transmission $T$ is simply given by,

$$
T=\frac{I(z)}{I_{0}}=(1-R)^{2} \frac{1}{1+\beta z I_{0}} .
$$

The experimentally measured non-linear transmission versus peak intensity $I \geq 13 \mathrm{GW} \mathrm{cm}^{-2}$ was performed on $0.5,3.8$ and $10 \mathrm{~mm}$ thick polycrystalline $\mathrm{ZnSe}$ substrates and results are shown in Fig. 6(a). The dashed line for the $0.5 \mathrm{~mm}$ represents the fit which includes the measured variation of $\beta$ from the $\mathrm{Z}$ scan of this sample, showing excellent agreement.
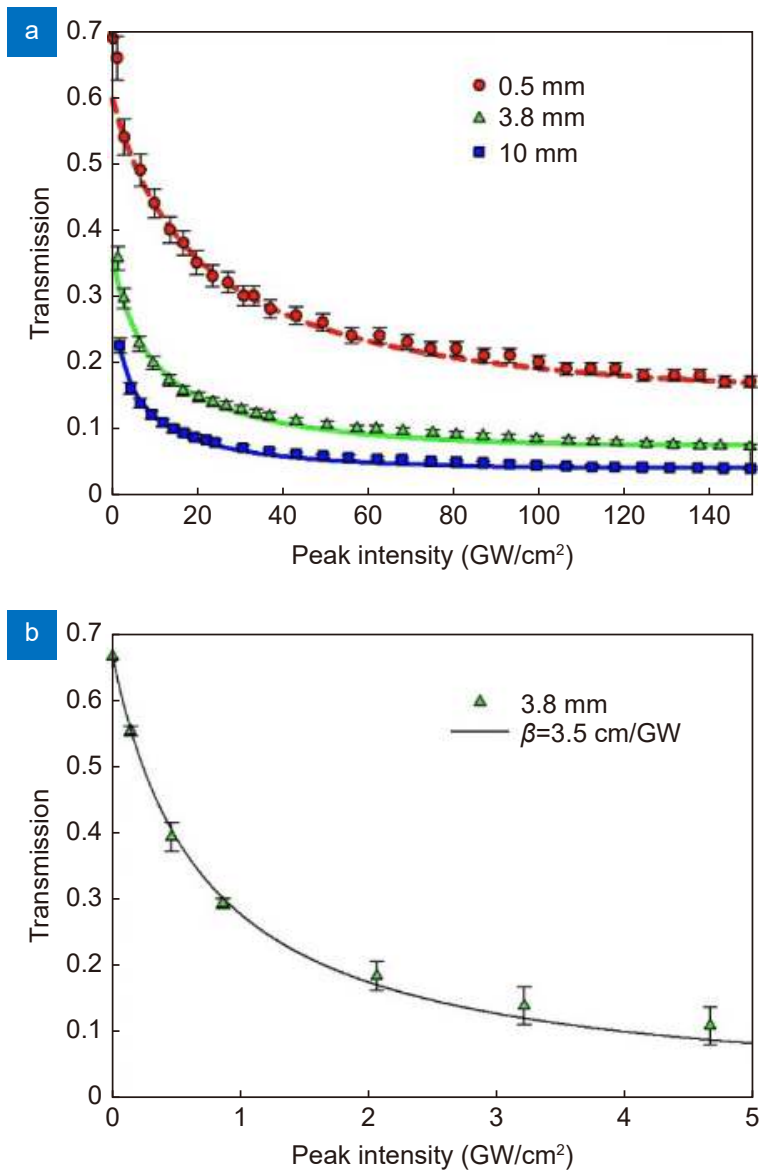

Fig. 6 | (a) The transmission of $0.5,3.8$ and $10 \mathrm{~mm}$ polycrystalline $\mathrm{ZnSe}$ at $\tau=200 \mathrm{fs}$ pulse length as a function of the incident peak intensity. The excellent fit (red dashed line) to the data for $0.5 \mathrm{~mm}$ sample includes the measured variation of $\beta$ from $Z$ scans. The nonlinear response is due to two-photon absorption and higher order. The solid lines represent the best fit to the data for thicker samples. (b) The transmission of $3.8 \mathrm{~mm}$ polycrystalline $\mathrm{ZnSe}$ at peak intensity below $5 \mathrm{GW} \mathrm{cm}^{-2}$ and fit to equation 4 with $\beta=3.5 \mathrm{~cm} \mathrm{GW}^{-1}$.

To compare $\beta$ near $I=1 \mathrm{GW} \mathrm{cm}^{-2}{ }^{21}$, we have measured NL transmission in the $3.8 \mathrm{~mm}$ thick sample with a collimated, $2.5 \mathrm{~mm}$ diameter beam. Results are shown in Fig. 6 (b) with best fit to Eq. (4), yielding $\beta=3.5 \pm 0.5 \mathrm{~cm}$ $\mathrm{GW}^{-1}$ - this value is in excellent agreement with Krauss and Wise's ${ }^{18}$ and close to that of Tseng et $\mathrm{al}^{21}$. Both used PC ZnSe.

$\beta$ is wavelength dependent and sensitive to the ratio $\left(\mathrm{h} v / \mathrm{E}_{\mathrm{b}}\right)$ where $E_{\mathrm{b}}=2.7 \mathrm{eV}$ is the band gap. Hence two photon absorption can occur only when $h v / E_{\mathrm{b}} \geq 0.5$, with maximum near $\left(h v / E_{\mathrm{b}}\right)=0.7^{41}$. At $775 \mathrm{~nm}, h v / E_{\mathrm{b}}=$ 0.59 while for $532 \mathrm{~nm}, h v / E_{\mathrm{b}}=0.86$ and thus expect 
$\beta(532)>\beta$ (775), supported by the data in Table $1^{41}$.

In the visible at $532 \mathrm{~nm}, \beta$ measured from NL transmission in PC ZnSe yield consistent results with $\langle\beta\rangle \sim$ $5.5 \pm 0.3 \mathrm{~cm} \mathrm{GW}^{-2} 13,14$ and $5.8 \pm 1.2 \mathrm{~cm} \mathrm{GW}^{-2}{ }^{15-17} \mathrm{re}-$ spectively. In SC ZnSe plates with faces cut parallel to the [111] crystallographic plane, $12.3<\beta<14.9 \mathrm{~cm} \mathrm{GW}^{-1}$ at $530 \mathrm{~nm}$ is hence much higher ${ }^{1}$.

In the NIR, in PC $\mathrm{ZnSe}^{18}$ at $\lambda=780 \mathrm{~nm},(75 \mathrm{fs}), \beta=3.5$ $\mathrm{cm} \mathrm{GW}^{-1}$ while in ref. ${ }^{21}$ at $\lambda=790 \mathrm{~nm},(200 \mathrm{fs}), \beta=2.7 \pm$ $0.3 \mathrm{~cm} \mathrm{GW}^{-1}$, whereas in SC ZnSe at $\lambda=710 \mathrm{~nm}^{19}, \beta \sim$ $6.9 \mathrm{~cm} \mathrm{GW}^{-1}$ and extrapolated to $775 \mathrm{~nm}$, we estimate $\beta \sim 6.5 \mathrm{~cm} \mathrm{GW}^{-1}$ so significantly higher than in PC material. In ref. ${ }^{20}$, also in SC ZnSe, the dispersion of $\beta$ was measured in detail over wavelength range $780-900 \mathrm{~nm}$, where, near $775 \mathrm{~nm}, \beta=5.1 \pm 0.6 \mathrm{~cm} \mathrm{GW}^{-1}$ in agreement with particular theoretical models. Thus, the twophoton absorption coefficient in SC ZnSe at low intensities appears to be approximately 1.7 times that in PC ZnSe.

\section{Fluorescence spectra characteristics}

Figure 7(a) shows the image of the fluorescence observed from $0.5 \mathrm{~mm}$ thick polycrystalline excited at $\lambda=$ $775 \mathrm{~nm}, \tau=200 \mathrm{fs}$, easily excited at ultrahigh intensity. Figure 7(b) shows a schematic diagram of the electronic excitation scheme in $\mathrm{ZnSe}$ so that simultaneous absorption of two photons excites electrons to the conduction band, followed by fast non-radiative relaxation (ps timescale $^{21}$ ) to the lowest vibrational level, $0.5 \mathrm{eV}$ below. The excited states then decay to ground state, via fluorescence, reaching thermal equilibrium. In addition, further sequential single photon during the fs pulse length from $3.2 \mathrm{eV}$ in the conduction band is relevant.

To measure the fluorescence emission spectra and decay kinetics, the spectra were collected by a spectrograph (Andor SR-303i, spectral resolution $0.1 \mathrm{~nm}$ ) equipped with an intensified charge coupled device (Andor ICCD-
DH 734). This fast gating intensified CCD camera can achieve time resolution down to 2 ns.

\section{Intensity dependence of the signal}

Figure 8 shows the experimental setup for measuring front (a) and rear (b) side fluorescence. The fluorescence was collected by an $f=50 \mathrm{~mm}$ lens and focused to a 0.2 NA fibre coupler, relaying fluorescence to the input slit of the Andor spectrometer. A UQG BG39 filter was used to block remaining NIR beam. Figure 8 (c) shows the typical fluorescence spectra of polycrystalline ZnSe with increasing excitation intensities. The peak position of the front side fluorescence is in the range of $472 \mathrm{~nm}-475$ $\mathrm{nm}$, moving to longer wavelengths with increasing intensity and all have a reasonably symmetric profile. On the other hand, the rear side spectra are all red shifted (about $6 \mathrm{~nm}$ ) and are asymmetric due to self-absorption in the material near the band gap edge. The peak wavelengths also can be seen to increase with intensity. Since linear absorption is negligible, we attributed the wavelength shifts with intensity to a thermal accumulation effect (slow) between pulses at $1 \mathrm{kHz}$ and (fast) acoustic density changes ${ }^{42}$. A red shift of a $\mathrm{ZnSe}$ with pump intensity was also reported in ref. ${ }^{3}$. The carrier densities increase with excitation intensities and more free carriers make the band filling effect possible. As a result, more energy will be lost in this scattering process, leading to the occurrence of the shift to longer wavelength.

The shift of the fluorescence spectra with incident intensity is listed in Table 2, based on the experimental data from Fig. 8. In Table 2, each peak position wavelength of the rear side is longer than the corresponding front side due to self-absorption near the band edge. The difference $\left(\Delta \lambda=\lambda_{\text {rear }}{ }^{-} \lambda_{\text {front }}\right)$ increases with the incident intensity but saturates above $I=100 \mathrm{GW} \mathrm{cm}^{-2}$.

To determine the degree of non-linearity, Fig. 9 shows
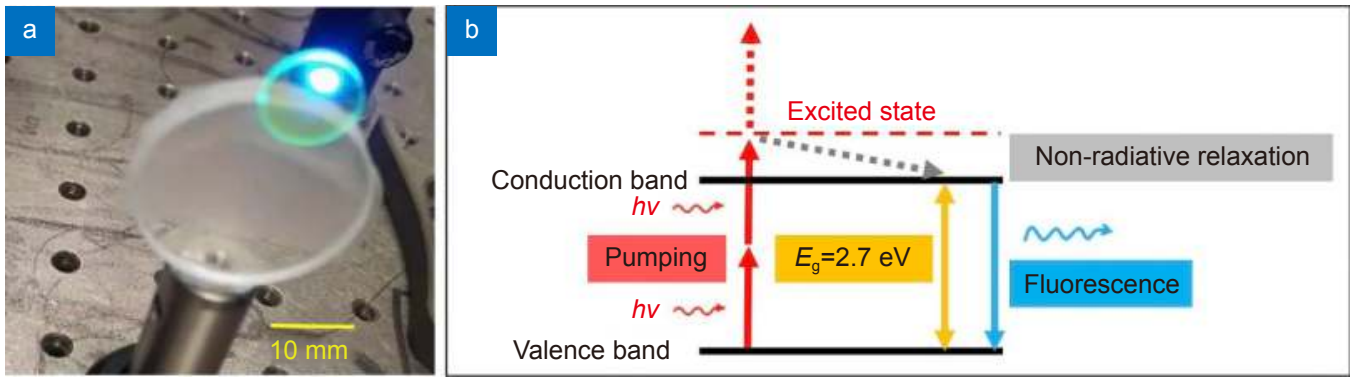

Fig. 7 | (a) Fluorescence of polycrystalline ZnSe pumped at $775 \mathrm{~nm}$. (b) Illustration of the two-photon absorption and fast relaxation to the top of the conduction band followed by spontaneous emission to the valence band. 


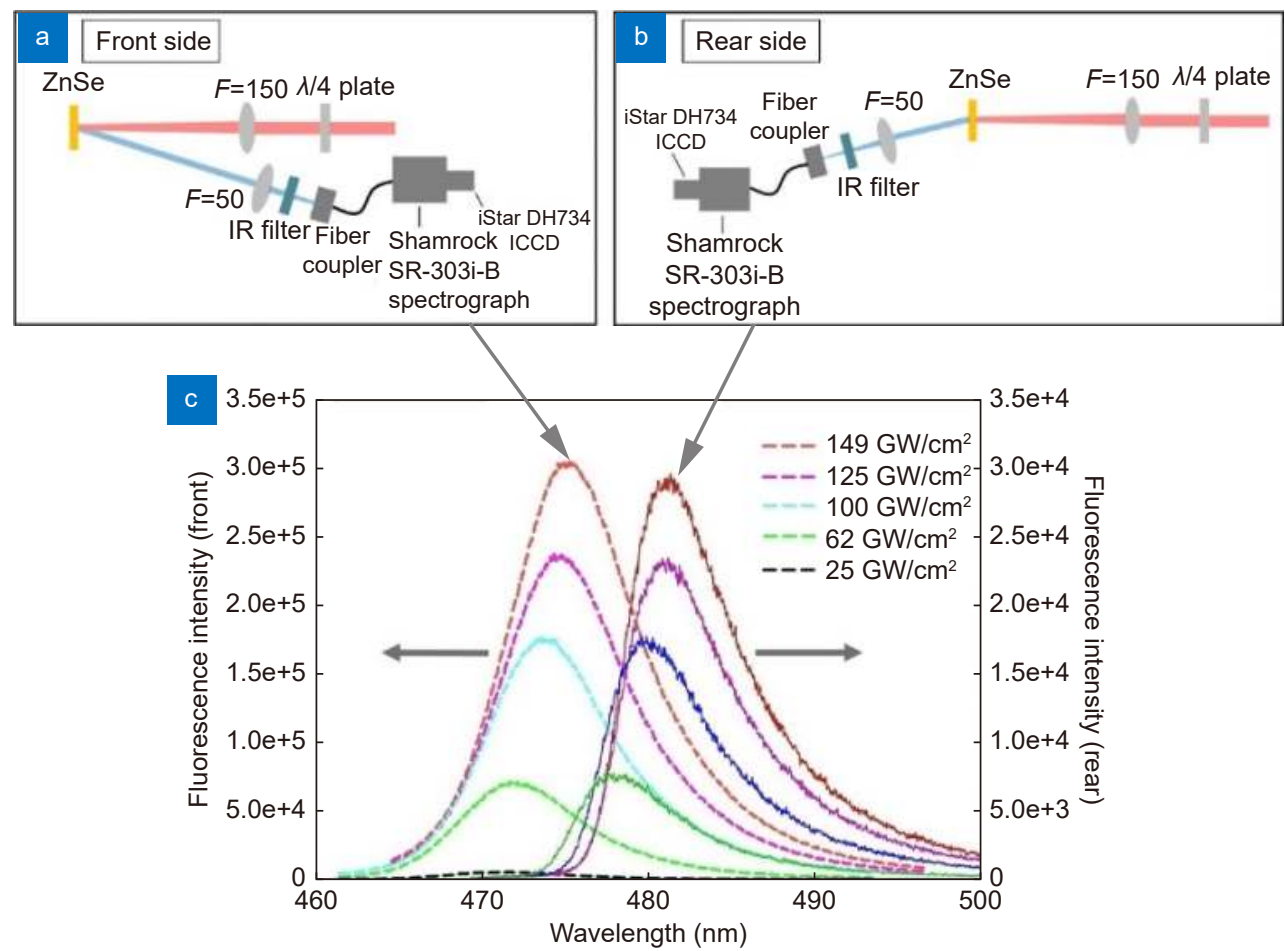

Fig. 8 | Front and rear side fluorescence spectra of $\mathbf{0 . 5} \mathbf{~ m m}$ thick polycrystalline ZnSe. Peak wavelengths increase with incident intensity and rear side fluorescence shows evidence of self-absorption near the band edge.

Table 2 | The shift of the fluorescence spectra maxima

\begin{tabular}{c|c|c|c}
\hline Peak intensity $\left(\mathrm{GW} \mathrm{cm} \mathrm{cm}^{-2}\right)$ & $\lambda_{\text {front }}(\mathrm{nm})$ & $\lambda_{\text {rear }}(\mathrm{nm})$ & $\Delta \Lambda(\mathrm{nm})$ \\
\hline 25 & 471.4 & 475.8 & 4.4 \\
62 & 472.0 & 478.1 & 6.1 \\
100 & 473.8 & 480.0 & 6.3 \\
125 & 474.8 & 481.1 & 6.3 \\
149 & 475.7 & 481.8 & 6.1 \\
\hline
\end{tabular}

the $\log$ (fluorescence signal intensity) versus log (incident intensity) measured when altering incident temporal pulse length from the Regen amplifier. The slopes are almost identical with NL exponent $m=2.7$ confirming that two photon absorption and higher order processes such as sequential photon absorption in the conduction band (RSA) are involved in the excitation process.

Figure 10 shows optical images of fluorescence observed when a $3.8 \mathrm{~mm}$ thick $\mathrm{ZnSe}$ window was pumped on the front surface with a collimated beam at $775 \mathrm{~nm}(\varphi=$ $2.5 \mathrm{~mm}$ ) with different temporal pulse lengths. Autocorrelation widths are quoted. As peak intensities decrease at longer pulse length, the fluorescence reduces in intensity and penetrates deeper within the material.

Figure 11 shows the effective NL absorption coefficient $\beta I_{0}\left(\mathrm{~cm}^{-1}\right)$ based on the data of Fig. 5(b) which drops significantly at lower intensity and converges to $\beta I_{0} \sim 26 \mathrm{~cm}^{-1}$ above $100 \mathrm{GW} \mathrm{cm} \mathrm{cm}^{-2}$. At intensity $I_{0}=25$
$\mathrm{GW} \mathrm{cm}-2, \beta I_{0} \sim 20 \mathrm{~cm}^{-1}$ and the coupling depth $d=1 / \beta I_{0} \sim$ $0.05 \mathrm{~cm}=0.5 \mathrm{~mm}$. The low intensity data (Fig. 6(b)) has also been added. Using $\beta=3.5 \mathrm{~cm} \mathrm{GW}^{-1}$ at low intensity, $\left(I_{0}=4,1.5,1 \mathrm{GW} \mathrm{cm}{ }^{-2}\right), \beta I_{0}=14 \mathrm{~cm}^{-1}, 5.3 \mathrm{~cm}^{-1}$ and 3.5 $\mathrm{cm}^{-1}$ respectively. As the two-photon fluorescence intensity should scale as $\left(I(z) / I_{0}\right)^{2}=\left[1 /\left(1+\beta I_{0} z\right)\right]^{2}$ then at the centre of the $3.8 \mathrm{~mm}$ sample, $(z=1.9)$ the fluorescence intensity, relative to that at the input face should reduce by factors of $0.1,0.25$ and 0.36 respectively. These factors look to be in approximate agreement with the relative intensities observed in Fig. 10(c-e).

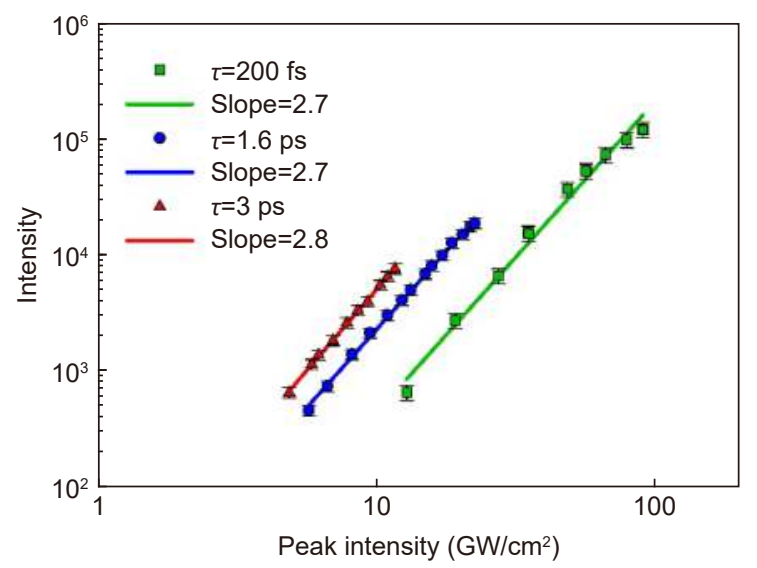

Fig. 9 | Log (fluorescence signal intensity) versus Log (incident intensity). 

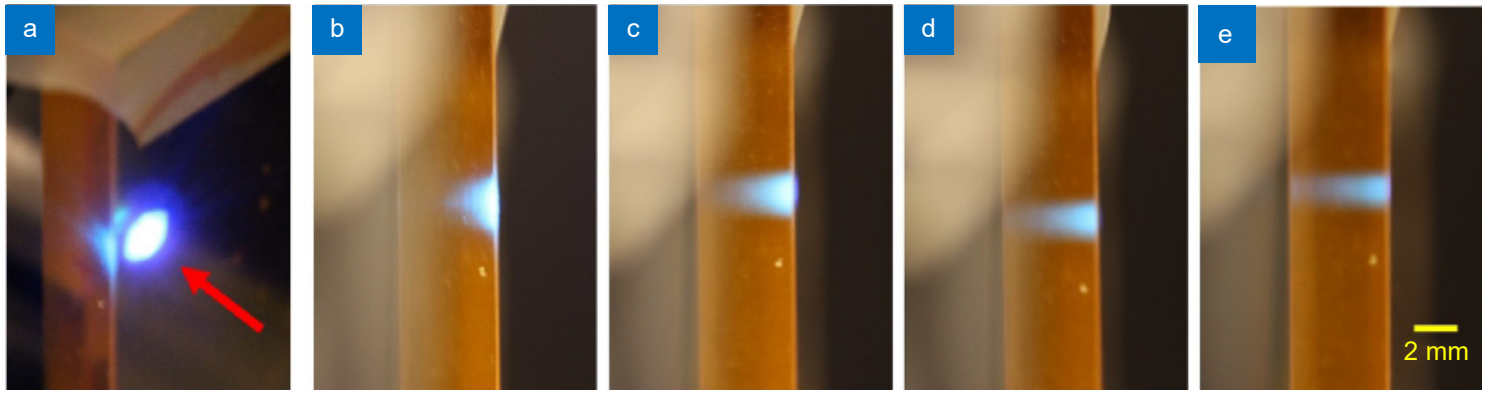

Fig. 10 Fluorescence penetration depth with different pulse duration. (a) pump the sample with $775 \mathrm{~nm}$ fs laser, (b) $\tau_{\mathrm{ac}}=0.26 \mathrm{ps}$, (c) $\tau_{\mathrm{ac}}=$ $1.7 \mathrm{ps},(\mathrm{d}) \tau_{\mathrm{ac}}=4.5 \mathrm{ps},(\mathbf{e}) \tau_{\mathrm{ac}}=6.5 \mathrm{ps}$. Sample thickness is $3.8 \mathrm{~mm}$. Fluorescence appears deeper in sample as incident intensity decreases. Peak intensities are $25 \mathrm{GW} \mathrm{cm}^{-2}, 4 \mathrm{GW} \mathrm{cm}^{-2}, 1.5 \mathrm{GW} \mathrm{cm}^{-2}, 1 \mathrm{GW} \mathrm{cm}^{-2}$ respectively.

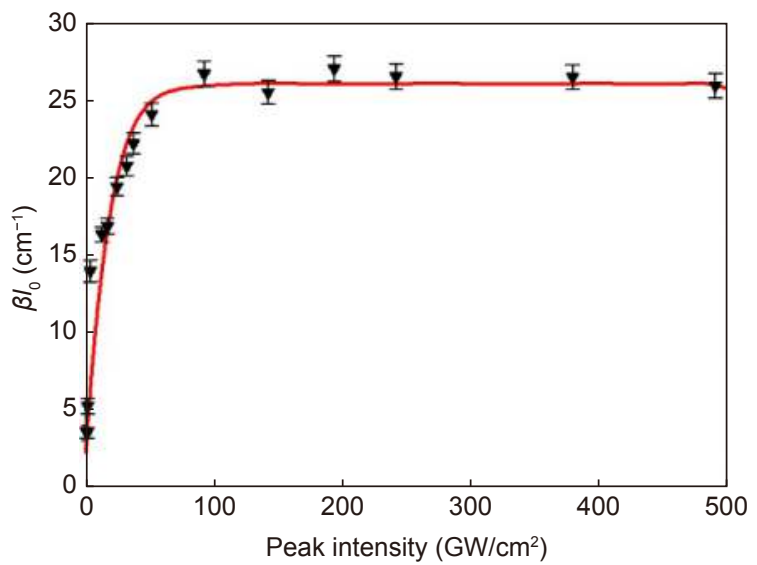

Fig. 11 | Effective NL absorption coefficient $\beta l_{0}\left(\mathrm{~cm}^{-1}\right)$ based on the data of Fig. 5(b)/Fig. 6(b) which drops significantly at lower intensity, increasing the coupling depth for 2-photon excitation. $\beta \mathrm{I}_{0}$ converges to $\sim 26 \mathrm{~cm}^{-1}$ above $100 \mathrm{GW} \mathrm{cm}{ }^{-2}$. These values are consistent with observed side fluorescence (Fig. 10).

\section{Fluorescence lifetime}

Fluorescence lifetime is the characteristic time an excited electron spends in the conduction band before emitting a photon and returning to the ground state, here the valence band. This was measured using the fast gate on the ICCD ( $2 \mathrm{~ns}$ gate width, gate delay $=1 \mathrm{~ns}$ ) which was synchronised to the laser pulse from the Pockels cell driver. Figure 12(a) shows the time resolved fluorescence where the decay time (1/e) was found to be $\tau_{1 / \mathrm{e}}=3.3 \pm 0.1 \mathrm{~ns}$ with linear polarisation at $10 \mathrm{GW} \mathrm{cm}^{-2}$. The fluorescence lifetime decays with increasing pump intensity, which indicates ion-ion energy exchange effects taking placing ${ }^{43}$.

Figure 12(b) shows the effect of incident polarisation on the fluorescence lifetime with intensity and linear polarisation has slightly higher lifetimes than that of circular polarisation likely due to stronger coupling (higher third order susceptibility $\xi^{(3)}$ with linear polarisation $)^{44}$. When the incident intensity is above $30 \mathrm{GW} \mathrm{cm}{ }^{-2}$, the fluorescence lifetime is almost constant. This phenomen-
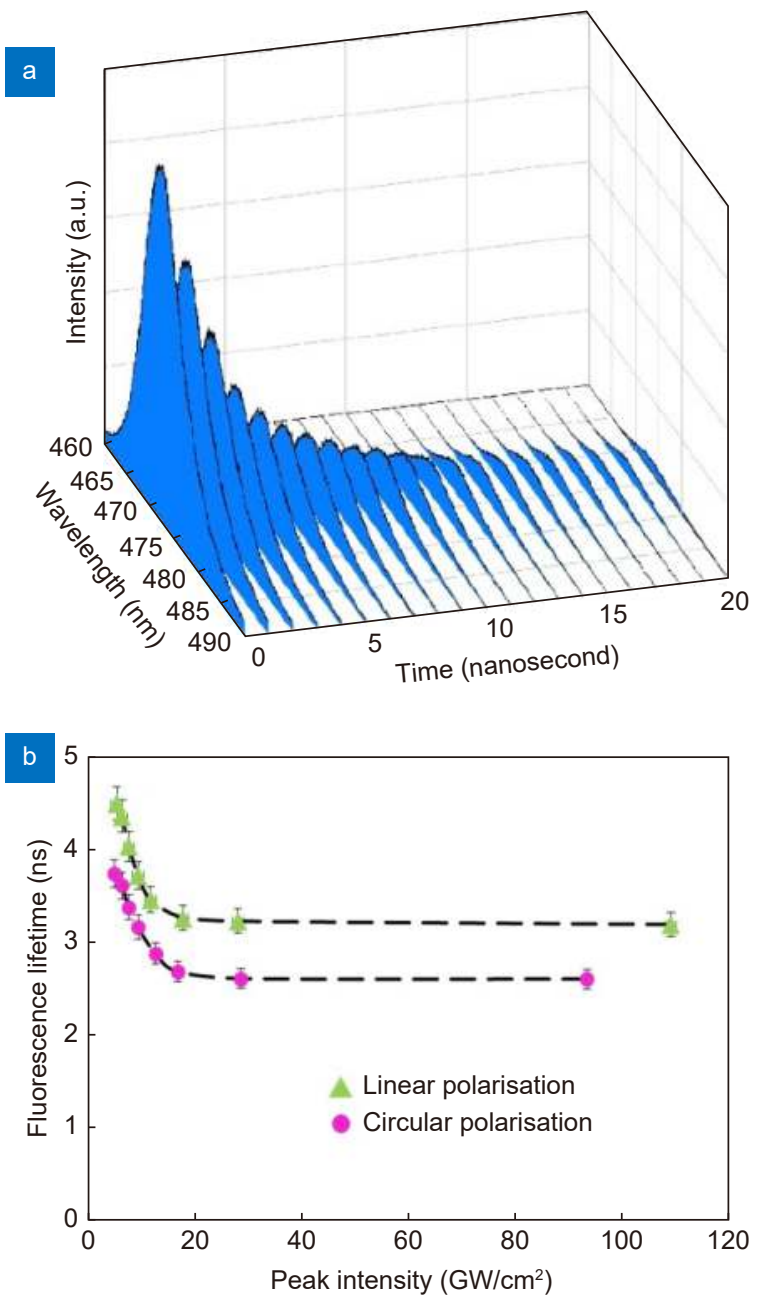

Fig. 12 | (a) Fluorescence decay curve against time. (b) polarisation effect on fluorescence lifetime $(\lambda=775 \mathrm{~nm}, \tau=200 \mathrm{fs})$. Linear polarisation results in longer upper state lifetimes while due to stronger coupling (third order susceptibility higher with linear polarisation).

on was also observed in biological cofactors ${ }^{45}$ while angular momenta of the absorbed photons and photo selection rules may be involved in the linear and circular polarisation excitation ${ }^{46}$.

Third order susceptibility, which is polarisation 
dependent, is given by $\chi^{(3)}=\operatorname{Re} \chi^{(3)}+\mathrm{i} \chi^{(3)}$, where the real part $\operatorname{Re} \chi^{(3)}$ is relevant to the nonlinear refractive index change $n_{2}$ and the imaginary part $\mathrm{i} \chi^{(3)}$ describes the two-photon absorption coefficient $\beta$. The nonlinear refraction coefficient of circular and linear polarised light is given by $n_{2}^{\text {cir }}=2 \operatorname{Re}\left(\chi^{3}\right) / 4 \varepsilon_{0} c n_{0}^{2}$ and $n_{2}^{\text {lin }}=3 \operatorname{Re}\left(\chi^{3}\right) /$ $4 \varepsilon_{0} c n_{0}^{2}$ respectively, where $\varepsilon_{0}$ represents the permittivity in the vacuum, $c$, the speed of the light ${ }^{47}$. Therefore, the ratio of $n_{2}^{\text {lin }} / n_{2}^{\text {cir }}=3 / 2$. In the case of $\beta$, proportional to $\mathrm{i} \chi^{(3)}$, coupling is stronger with linear polarisation as the tensor $\chi^{(3)}$ has two components for linear polarisation and only one component for circular polarisation ${ }^{20,41}$.

The transmission through ZnSe with incident peak intensity was measured at linear and circular polarisation, with slightly higher transmission of circular polarisation. However, the intensity of the fluorescence signal with linear polarisation was more obvious, which is approximately $\times 1.1-1.2$ times higher than that of circular polarisation (Fig. 13).

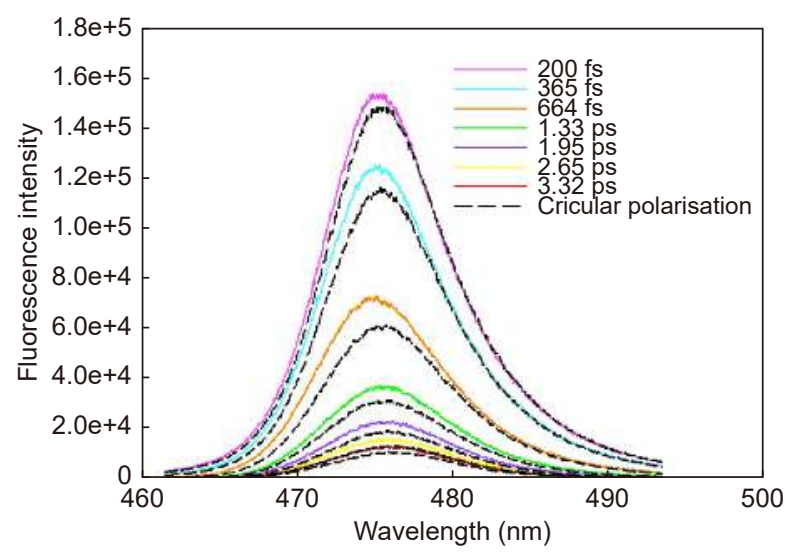

Fig. 13 | Fluorescence signal intensity with linear (solid lines) and circular polarisation (dash lines).

\section{Stimulated emission}

Stimulated emission and two-photon pumped blue lasing in single crystal $\mathrm{ZnSe}$ was previously reported in short cavities using the crystal end facets as feedback elements $^{3,35}$. To investigate stimulated emission in polycrystalline ZnSe we placed a $0.5 \mathrm{~mm} \mathrm{ZnSe}$ substrate inside a resonant cavity with the crystal tilted near Brewster's angle to minimise reflections losses. Brewster's angle was first checked by mounting the ZnSe on a precision rotation stage, and the reflectance measured when rotating the ZnSe. The P (horizontal) and S (vertical) polarisation were controlled by rotating a $\lambda / 2$ plate ahead of the crystal. The measured Brewster's angle of ZnSe at 775 $\mathrm{nm}$ was $70^{\circ}$ (Fig. 14), as expected from theory, $\theta_{\mathrm{B}}=$ $\tan ^{-1} n=\tan ^{-1} 2.53=68.4^{\circ}$.

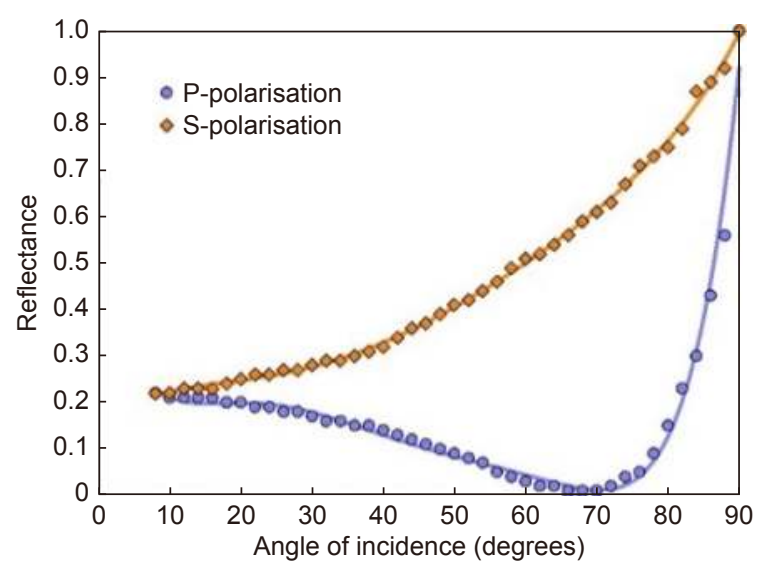

Fig. 14 | Reflectance as a function of the incidence angle and polarisation of polycrystalline ZnSe showing that Brewster's angle is near $70^{\circ}$ as expected.

Figure 15 shows the experimental setup of the optical cavity and detection set-up. The sample optically polished on one edge and pumped near $20^{\circ}$ from normal, forming a gain region across the edge. The cavity was formed by a curved high reflector (spherical Al mirror, radius $r=200 \mathrm{~mm}, R>90 \%, 400-700 \mathrm{~nm}$ ) and plane dielectric output coupler $(\mathrm{O} / \mathrm{C})$ with reflectivity $R_{\mathrm{OC}} \sim$ $55 \%$ at $475 \mathrm{~nm}$. This $\mathrm{O} / \mathrm{C}$ also allowed alignment of the cavity by using a green $\mathrm{HeNe}$ laser at $543 \mathrm{~nm}$. The cavity emission was collected with a $50 \mathrm{~mm}$ focal length lens and fiber coupler to the spectrometer. A UQG BG39 cut off filter was used to remove any remaining $775 \mathrm{~nm}$ scatter. The stability of the laser cavity was modelled by WinLase 2.1 Pro with stability parameter 1.0 at $d_{2}=55$ $\mathrm{mm}$, dropping only to 0.99 at $d_{2}=45 \mathrm{~mm} / 55 \mathrm{~mm}$, which is highly stable. The short cavity length allows up to $3 \sim 4$ round trips for gain based on the stimulated fluorescence lifetime of $3.3 \mathrm{~ns}$ at the high intensity (Fig. 12(b)). The pumping with linear polarisation has longer lifetime, allowing more cavity round trips.

Figure 16 shows the observed output emission spectra with pump intensity within the $10 \mathrm{~cm}$ resonator under two-photon excitation at $775 \mathrm{~nm} / 1 \mathrm{kHz}$. As pulse intensity increases, the amplified spectrum width decreases while emission intensity grows significantly. At pump intensity $I=148 \mathrm{GW} \mathrm{cm}^{-2}$, the peak wavelength $\lambda=475 \mathrm{~nm}$ with $\Delta \lambda_{\text {FWHM }} \sim 2.8 \mathrm{~nm}$. Spectral narrowing is a strong indication of stimulated emission in polycrystalline $\mathrm{ZnSe}$. The dotted line represents the spectrum observed when the Aluminium mirror was blocked, with 


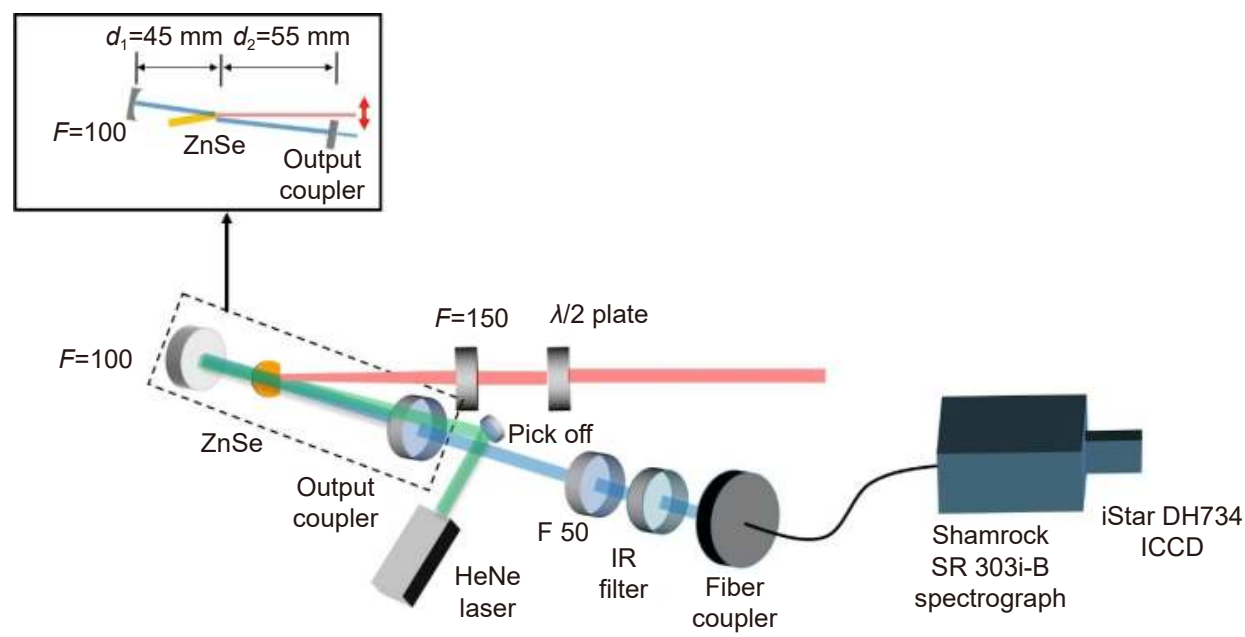

Fig. 15 | Schematic diagram of resonant cavity with spectral analysis. The curved mirror is Aluminium coated $(R>90 \%)$ while the flat dielectric output coupler had reflectivity $R \sim 55 \%$ at $475 \mathrm{~nm}$. The arrow in the inset (plan view) shows the linear polarisation direction.

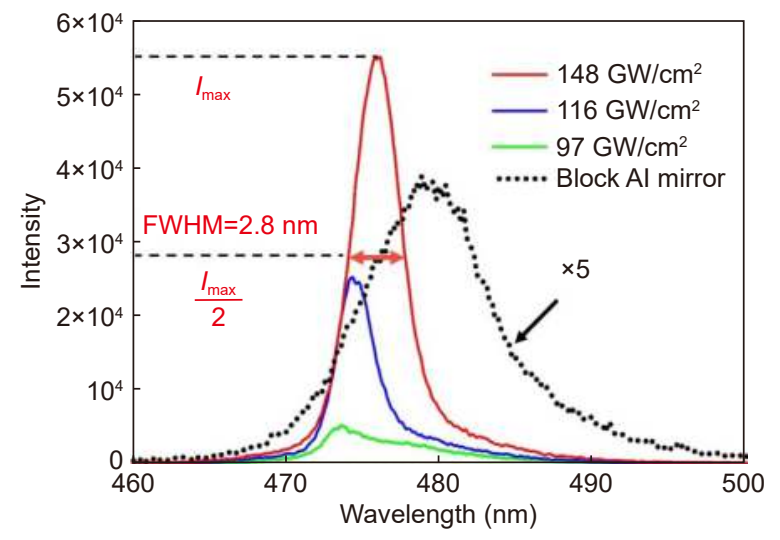

Fig. 16 | Spectra of stimulated emission output spectrum from polycrystalline $\mathrm{ZnSe}$ within the resonant cavity $(\lambda=775 \mathrm{~nm}, \tau=$ $200 \mathrm{fs})$. The solid lines and dotted line represent the spectrum within the cavity and with blocked high reflective mirror respectively.

\section{$\Delta \lambda_{\mathrm{FWHM}}=11 \mathrm{~nm}$.}

The intensity of the emission spectra from the cavity with pump intensity is shown in Fig. 17. The intensity increases significantly above $I=80 \mathrm{GW} \mathrm{cm}^{-2}$ with the slope changing from $S=2.4$ to $S=6.1$. This intensity characteristic along with the spectral narrowing are a strong indication of stimulated emission, similar to the results contained in $\mathrm{ZnO}$ nanorods where a superlinear stimulated fluorescence signal was observed ${ }^{48}$.

\section{Conclusions}

Linear and nonlinear optical properties of polycrystalline $\mathrm{ZnSe}$ have been studied in detail when excited at 775 $\mathrm{nm} / 1 \mathrm{kHz}$ and at ultrahigh intensity. As ZnSe is transparent at $775 \mathrm{~nm}$, absorption occurs primarily by nonlinear two-photon absorption. The two-photon absorption coefficient $\beta$ was found to be intensity dependent, imply-

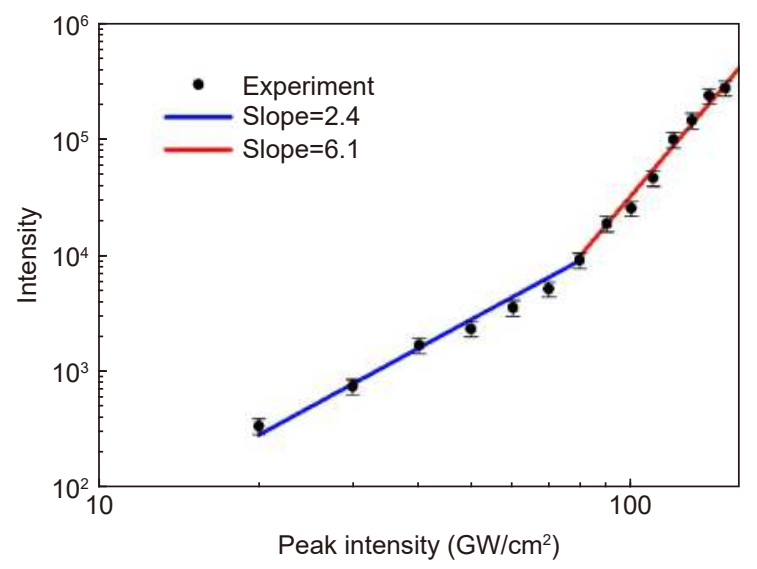

Fig. 17 The intensity of the emission signal from the cavity versus pump intensity ( $\tau=\mathbf{2 0 0} \mathbf{f s}$ ). Above $80 \mathrm{GW} \mathrm{cm}^{-2}$, the slope increase infers gain within the cavity.

ing that RSA (involving sequential photon absorption) is also a relevant nonlinear process. $\beta$ was measured to be $1.3 \mathrm{~cm} \mathrm{GW}^{-1}$ at intensity $I=13 \mathrm{GW} \mathrm{cm}^{-2}$, decreasing to $\beta=0.05 \mathrm{~cm} \mathrm{GW}^{-1}$ at $490 \mathrm{GW} \mathrm{cm}^{-2}$. In the low intensity regime with $I<5 \mathrm{GW} \mathrm{cm}^{-2}$, we measured $\beta=3.5 \pm 0.5 \mathrm{~cm}$ $\mathrm{GW}^{-1}$ in excellent agreement with the data from Krauss and $\mathrm{Wise} \mathrm{i}^{18}$ and in good agreement with that of Tseng et $\mathrm{a}^{21}$. The transmission through substrates with varying thickness was modelled analytically and in excellent agreement with experimental data observed from a 0.5 mm thick sample, allowing for varying $\beta$.

In polycrystalline $\mathrm{ZnSe}$ the grain size is quoted to be < $100 \mu \mathrm{m}$ from the supplier. The crystals, which are isotropic are randomly oriented and can allow quasi-phase matching in difference frequency generation (DFG) when the coherence length $\Lambda$ in the polycrystalline $\mathrm{ZnSe}$ is similar to the size of the grains ${ }^{49}$. Nonlinear 
conversion to second harmonic-generation (SHG) and sum-frequency generation (SFG) in polycrystalline $\mathrm{ZnSe}$ has also been demonstrated where the SF signals appeared in bright spots around the SHG due to phase matching in grains with particular orientations ${ }^{50}$. In the case of two-photon absorption, as there is no such phase matching requirement in this isotropic material, one might assume that in polycrystalline $\mathrm{ZnSe}$, the random grain orientations may average out, yielding the same $\beta$ as single crystalline $\mathrm{ZnSe}$. However, the nonlinear optical response in single crystal $\mathrm{ZnSe}$ is not isotropic and so $\chi^{(3)}$ depends on the relative orientation of the light polarisation to the crystal axis ${ }^{20}$ which may average over oriented grains to a different value. By comparing the measured $\beta$ 's near $775 \mathrm{~nm}$ in both single crystal and polycrystalline $\mathrm{ZnSe}^{18-21}$ we find that the $\beta(\mathrm{SC}) \sim 1.7 \beta(\mathrm{PC})$.

Broad blue fluorescence from polycrystalline $\mathrm{ZnSe}$ was observed with an upper state lifetime $~ 3.5 \mathrm{~ns}$, and comparison of fluorescence spectra from both front and rear surfaces displayed peak shifts of $\sim 6 \mathrm{~nm}$, intensity dependent with a nonlinear gradient $m=2.7$ so that twophoton plus excited state absorption via RSA (sequential or free carrier photon absorption) is likely involved in NL excitation. By integrating the $0.5 \mathrm{~mm}$ polycrystalline sample into a stable resonant cavity with length $10 \mathrm{~cm}$, stimulated emission was observed, confirmed by significant spectral narrowing from $\Delta \lambda=11 \mathrm{~nm}$ (cavity blocked) to $\Delta \lambda=2.8 \mathrm{~nm}$. Although a lasing threshold was not observed, results suggest that a higher reflectivity output coupler, combined with crystal cooling, may allow laser output. The presented results confirm that available polycrystalline ZnSe substrates have sufficient purity and low defect density to warrant further investigation.

\section{References}

1. Derkowska B, Sahraoui B, Phu XN, Bala W. Nonlinear optical properties in ZnSe crystals. Proc SPIE 4412, 337-341 (2001).

2. Gavrushchuk EM. Polycrystalline zinc selenide for IR optical applications. Inorg Mater 39, 883-899 (2003).

3. Yang XH, Hays JM, Shan W, Song JJ, Cantwell E. Two-photon pumped blue lasing in bulk ZnSe and ZnSSe. Appl Phys Lett 62 , 1071-1073 (1993).

4. Yang $X \mathrm{H}$, Hays J, Shan W, Song JJ, Cantwell E et al. Optically pumped lasing of ZnSe at room temperature. Appl Phys Lett 59, 1681-1683 (1991).

5. Adachi S, Taguchi T. Optical properties of ZnSe. Phys Rev B 43, 9569-9577 (1991).

6. Aven M, Marple DTF, Segall B. Some electrical and optical properties of ZnSe. J Appl Phys 32, 2261-2265 (1961).

7. Klein CA, Miller RP, Stierwalt DL. Surface and bulk absorption characteristics of chemically vapor-deposited zinc selenide in the infrared. Appl Opt 33, 4304-4313 (1994).

8. Okhrimchuk AG, Mezentsev VK, Schmitz H, Dubov M, Bennion I. Cascaded nonlinear absorption of femtosecond laser pulses in dielectrics. Laser Phys 19, 1415-1422 (2009).

9. Gautron J, Raisin C, Lemasson P. Optical and electro-optical behaviour of polished and etched zinc selenide single crystals. $J$ Phys D Appl Phys 15, 153-161 (1982).

10. Hite GE, Marple DTF, Aven M, Segall B. Excitons and the absorption edge in ZnSe. Phys Rev 156, 850-859 (1967).

11. Palik ED. Handbook of Optical Constants of Solids Vol. 2. (Academic Press, Boston, 1991).

12. Jones $\mathrm{G}$, Woods J. The electrical properties of zinc selenide. J Phys D Appl Phys 9, 799-810 (1976).

13. Van Stryland EW, Woodall MA, Vanherzeele H, Soileau MJ. Energy band-gap dependence of two-photon absorption. Opt Lett 10, 490-492 (1985).

14. Van Stryland EW, Vanherzeele H, Woodall MA, Soileau MJ, Smirl AL et al. Two photon absorption, nonlinear refraction, and optical limiting in semiconductors. Opt Eng 24, 244613 (1985).

15. Sheik-Bahae M, Said AA, Wei TH, Hagan DJ, Van Stryland EW. Sensitive measurement of optical nonlinearities using a single beam. IEEE J Quantum Electron 26, 760-769 (1990).

16. Said AA, Sheik-Bahae M, Hagan DJ, Wei TH, Wang J et al. Determination of bound-electronic and free-carrier nonlinearities in ZnSe, GaAs, CdTe, and ZnTe. J Opt Soc Am B 9, 405-414 (1992).

17. Hutchings DC, Van Stryland EW. Nondegenerate two-photon absorption in zinc blende semiconductors. J Opt Soc Am B 9, 2065-2074 (1992).

18. Krauss TD, Wise FW. Femtosecond measurement of nonlinear absorption and refraction in CdS, ZnSe, and ZnS. Appl Phys Lett 65, 1739-1741 (1994).

19. Balu M, Hales J, Hagan DJ, Van Stryland EW. Dispersion of nonlinear refraction and two-photon absorption using a whitelight continuum Z-scan. Opt Express 13, 3594-3599 (2005).

20. Dabbicco M, Brambilla M. Dispersion of the two-photon absorption coefficient in ZnSe. Solid State Commun 114, 515-519 (2000).

21. Tseng KY, Wong KS, Wong GKL. Femtosecond time-resolved Z-scan investigations of optical nonlinearities in ZnSe. Opt Lett 21, 180-182 (1996).

22. Van Stryland EW, Woodall MA, Williams WE, Soileau MJ. Twoand three-photon absorption in semiconductors with subsequent absorption by photogenerated carriers. In Bennett $\mathrm{H}$, Guenther A, Milam D, Newnam B. Laser Induced Damage in Optical Materials 589-600 (ASTM International, West Conshohocken, PA, 1983); https://doi.org/10.1520/STP37286S.

23. Major A, Aitchison JS, Smith PWE, Sorokin E, Sorokina IT. Zscan characterization of the nonlinear refractive index of single crystal $\mathrm{ZnSe}$ in the 1.20-1.95 $\mu \mathrm{m}$ wavelength range. Proc SPIE 5971, 59710H (2005).

24. Werner K, Hastings MG, Schweinsberg A, Wilmer BL, Austin D et al. Ultrafast mid-infrared high harmonic and supercontinuum generation with $n_{2}$ characterization in zinc selenide. Opt Express 27, 2867-2885 (2019).

25. Colak S, Fitzpatrick BJ, Bhargava RN. Electron beam pumped II-VI lasers. J Cryst Growth 72, 504-511 (1985).

26. Potts JE, Smith TL, Cheng H, Yang B, Wessels BW. Electronbeam-pumped lasing in epitaxial ZnSe thin films. J Cryst Growth 86, 935-941 (1988). 
27. Seymour R, Fitzpatrick B, Bhargava R. Optically pumped stimulated emission in ZnSe. IEEE J Quantum Electron 14, 462-463 (1978).

28. Zmudzinski CA, Guan Y, Zory PS. Room temperature photopumped ZnSe lasers. IEEE Photonics Technol Lett 2, 94-96 (1990).

29. Suemune I, Yamada K, Masato $H$, Kan $Y$, Yamanishi M. Lasing in a $\mathrm{ZnS}_{0.12} \mathrm{Se}_{0.88} / \mathrm{ZnSe}$ multilayer structure with photopumping. Appl Phys Lett 54, 981-983 (1989).

30. Mitsuyu T, Suzuki T, Tomimasu T. Luminescence from ZnSe excited by picosecond mid-infrared FEL pulses. NuCl Instrum Methods Phys Res B Beam Interact Mater Atoms 144, 172-175 (1998).

31. Catalano IM, Cingolani A, Ferrara M, Lugarà M. Stimulated photoluminescence of ZnSe. Solid State Commun 43, 371-374 (1982).

32. Johnston WD Jr. Coulomb interaction in semiconductor lasers. Phys Rev B 6, 1455-1464 (1972).

33. Daly TP, Mahr H. Picosecond spectroscopy of CdSe at high excitation densities. Phys Rev B 29, 5591-5601 (1984).

34. Newbury PR, Shahzad K, Cammack DA. Stimulated emission via inelastic exciton - exciton scattering in ZnSe epilayers. Appl Phys Lett 58, 1065-1067 (1991).

35. Baltrameyunas RA, Gladyshchuk AA, Gribkovskiĭ VP, Kuokshtis ÉP, Yablonskiĭ GP. Luminescence and lasing of ZnSe single crystals subjected to one- and two-photon excitation. Sov $J$ Quantum Electron 11, 539-541 (1981).

36. Era K, Langer DW. Luminescence of ZnSe near the band edge under strong laser light excitation. J Lumin 1 -2, 514-527 (1970).

37. Weber H. Two-photon-absorption laws for coherent and incoherent radiation. IEEE J Quantum Electron 7, 189-195 (1971).

38. Couris S, Koudoumas E, Ruth AA, Leach S. Concentration and wavelength dependence of the effective third-order susceptibility and optical limiting of $\mathrm{C}_{60}$ in toluene solution. J Phys B At Mol Opt Phys 28, 4537-4554 (1995).

39. Prakash D, Shaaban ER, Shapaan M, Mohamed SH, Othman AA et al. Thickness-dependent dispersion parameters, energy gap and nonlinear refractive index of ZnSe thin films. Mater Res Bull 80, 120-126 (2016).

40. Wang XF, Jia TQ, Li XX, Li CB, Feng DH et al. Ablation and ultrafast dynamics of zinc selenide under femtosecond laser irra- diation. Chin Opt Lett 3, 615-617 (2005).

41. Boyd RW. Nonlinear Optics 3rd ed (Academic Press, San Diego, 2008).

42. Ganeev RA, Ryasnyansky AI, Ishizawa N, Baba M, Suzuki M et al. Two- and three-photon absorption in $\mathrm{CS}_{2}$. Opt Commun 231, 431-436 (2004).

43. Yan $\mathrm{KL}, \mathrm{Vu} \mathrm{K}$, Madden $\mathrm{S}$. Internal gain in Er-doped $\mathrm{As}_{2} \mathrm{~S}_{3}$ chalcogenide planar waveguides. Opt Lett 40, 796-799 (2015).

44. Krauss TD, Ranka JK, Wise FW, Gaeta AL. Measurements of the tensor properties of third-order nonlinearities in wide-gap semiconductors. Opt Lett 20, 1110-1112 (1995).

45. Blacker TS, Nicolaou N, Duchen MR, Bain AJ. Polarized twophoton absorption and heterogeneous fluorescence dynamics in NAD(P)H. J Phys Chem B 123, 4705-4717 (2019).

46. de Vito G, Ricci P, Turrini L, Gavryusev V, Müllenbroich $C$ et al. Effects of excitation light polarization on fluorescence emission in two-photon light-sheet microscopy. Biomed Opt Express 11, 4651-4665 (2020).

47. Schimpf DN, Eidam T, Seise E, Hädrich S, Limpert J et al. Circular versus linear polarization in laser-amplifiers with Kerr-nonlinearity. Opt Express 17, 18774-18781 (2009).

48. Torres-Torres C, Trejo-Valdez M, Sobral H, Santiago-Jacinto P, Reyes-Esqueda JA. Stimulated emission and optical third-order nonlinearity in Li-doped ZnO nanorods. J Phys Chem C 113, 13515-13521 (2009).

49. Baudrier-Raybaut M, Haïdar R, Kupecek P, Lemasson P, Rosencher $\mathrm{E}$. Random quasi-phase-matching in bulk polycrystalline isotropic nonlinear materials. Nature 432, 374-376 (2004).

50. Chinh TD, Seibt W, Siegbahn K. Dot patterns from second-harmonic and sum-frequency generation in polycrystalline ZnSe. $J$ Appl Phys 90, 2612-2614 (2001).

\section{Author contributions}

Q. L. Li conducted the experiments and wrote the paper. W. Perrie conceived the work and directed the experiments. Z. Q. Li performed the external optical transmission measurements. S. P. Edwardson and G. Dearden supervised the research. All authors discussed the results and commented on the manuscript.

\section{Competing interests}

The authors declare no competing financial interests. 